\title{
Gamma synuclein is a novel Twist1 target that promotes TGF- $\beta$-induced cancer cell migration and invasion
}

Ting Shao ${ }^{1}$, Peiying Song ${ }^{1}$, Hui Hua ${ }^{2}$, Hongying Zhang ${ }^{1}$, Xiangmin Sun ${ }^{1}$, Qingbin Kong ${ }^{1}$, Jiao Wang ${ }^{3}$, Ting Luo ${ }^{4}$ and Yangfu Jiang (10)

\begin{abstract}
Transforming growth factor $\beta$ (TGF- $\beta$ ) is critical for embryonic development, adult tissue homeostasis, and tumor progression. TGF- $\beta$ suppresses tumors at early stage, but promotes metastasis at later stage through oncogenes such as Twist1. Gamma-synuclein (SNCG) is overexpressed in a variety of invasive and metastatic cancer. Here, we show that TGF- $\beta$ induces SNCG expression by Smad-Twist1 axis, thus promoting TGF- $\beta$ - and Twist1-induced cancer cell migration and invasion. We identify multiple Twist1-binding sites (E-boxes) in SNCG promoter. Chromatin immunoprecipitation and luciferase assays confirm the binding of Twist1 to the E-boxes of SNCG promoter sequence (-129/-1026 bp). Importantly, the Twist1-binding site close to the transcription initiation site is critical for the upregulation of SNCG expression by TGF- $\beta$ and Twist1. Mutations of Twist1 motif on the SNCG promoter constructs markedly reduces the promoter activity. We further show that TGF- $\beta$ induces Twist1 expression through Smad thereby enhancing the binding of Twist1 to SNCG promoter, upregulating SNCG promoter activity and increasing SNCG expression. SNCG knockdown abrogates TGF- $\beta$ - or Twist1-induced cancer cell migration and invasion. Finally, SNCG knockdown inhibits the promotion of cancer metastasis by Twist1. Together, our data demonstrate that SNCG is a novel target of TGF- $\beta$ Smad-Twist1 axis and a mediator of Twist1-induced cancer metastasis.
\end{abstract}

\section{Introduction}

Gamma-synuclein (SNCG) is one of the three members of the synuclein family ( $\alpha$-synuclein/SNCA, $\beta$-synuclein/ SNCB, and SNCG), which are preferentially expressed in the brain and peripheral nervous system. SNCA is found mainly at presynaptic terminals where it plays a role in clustering synaptic vesicles and promoting SNAREcomplex assembly thereby regulating the release of neurotransmitters $^{1,2}$. While the biophysical properties of native SNCA remains controversial $^{3,4}$, SNCA is

\footnotetext{
Correspondence: Yangfu Jiang (jyangfu@scu.edu.cn)

${ }^{1}$ State Key Laboratory of Biotherapy, Section of Oncogene, Cancer Center, West China Hospital, Sichuan University and Collaboratory Inovation Center for Biotherapy, Chengdu, China

${ }^{2}$ Laboratory of Stem Cell Biology, West China Hospital, Sichuan University, Chengdu, China

Full list of author information is available at the end of the article.

Edited by Z-X Xiao
}

susceptible to aggregation, which is involved in Alzheimer's disease, Parkinson disease, dementia with Lewy bodies, and multiple system atrophy ${ }^{5,6}$. SNCB and SNCG, however, have antagonistic effects on SNCA aggregation ${ }^{7}$. Normally, SNCG is expressed in peripheral neurons, ocular tissue, and adipose ${ }^{8,9}$. In addition, SNCG is overexpressed in various types of human tumors, such as breast, ovary, colon, liver, and cervical cancer ${ }^{10-13}$. Overexpression of SNCG in cancer cells may be due to aberrant demethylation of $\mathrm{CpG}$ islands within the promoter, AP1 transactivation, and insulin-like growth factor signaling ${ }^{13-15}$. SNCG promotes cancer metastasis and cancer cell survival under stresses ${ }^{16-19}$. Upon interacting with heat-shock proteins (HSPs), SNCG acts as a cochaperone of HSP to stimulate estrogen receptor signaling $^{20}$. The stability or activity of multiple kinases, such as IGF-1R, Akt, and ERK1/2, is enhanced by SNCG ${ }^{14,19,21}$.

\section{(c) The Author(s) 2018}

(c) (i) Open Access This article is licensed under a Creative Commons Attribution 4.0 International License, which permits use, sharing, adaptation, distribution and reproduction c. in any medium or format, as long as you give appropriate credit to the original author(s) and the source, provide a link to the Creative Commons license, and indicate if changes were made. The images or other third party material in this article are included in the article's Creative Commons license, unless indicated otherwise in a credit line to the material. If material is not included in the article's Creative Commons license and your intended use is not permitted by statutory regulation or exceeds the permitted use, you will need to obtain permission directly from the copyright holder. To view a copy of this license, visit http://creativecommons.org/licenses/by/4.0/. 
Moreover, SNCG interacts with BubR1 to regulate cell cycle checkpoint ${ }^{22}$. Therefore, SNCG may promote tumor progression and drug resistance through multiple mechanisms. Overexpression of SNCG is a predictive marker for poor prognosis in human breast cancer ${ }^{11}$.

Similar to SNCG, the basic helix-loop-helix transcription factor Twist1 acts as an oncogene in many cancers including breast cancer, hepatocellular carcinoma, pancreatic carcinoma, and neuroblastoma ${ }^{23-25}$. Twist1 can be activated by a variety of signal transduction pathways, including signal transducer and activator of transcription 3 (STAT3), Ras, mitogen-activated protein kinase (MAPK), and Wnt signaling ${ }^{26,27}$. Twist1 preferentially binds to E-box (5'-CANNTG-3') consensus sites in the promoter of target genes and regulate gene expression ${ }^{28}$. Activated Twist1 upregulates $\mathrm{N}$-cadherin and downregulates E-cadherin, which are the hallmarks of epithelial-mesenchymal transition (EMT), a process characterized by loss of cell-cell contacts and acquisition of fibroblastic phenotypes ${ }^{29}$. EMT is important for embryonic development, cancer metastasis, and drug resistance $^{30,31}$. In addition, Twist1 upregulates the expression of matrix metalloproteinases, which degrades the extracellular matrix (ECM) and paves the way for cell dissemination ${ }^{27}$. Moreover, Twist1 promotes cancer metastasis by regulating multiple processes involved in metastasis, such as angiogenesis, invasion, migration, extravasation, and chromosomal instability ${ }^{32,33}$. Twist1 is responsible for the maintenance of cancer stem cells and the development of chemotherapy resistance ${ }^{34-36}$.

Twist1 expression can be induced by transforming growth factor- $\beta$ (TGF- $\beta$ ), a pleiotrophic cytokine that may inhibit cell proliferation, promote cell differentiation, invasion, migration, and immune evasion ${ }^{37,38}$. While TGF- $\beta$ inhibits tumorigenesis at the early stage, it often promotes tumor progression at the late stage. During tumor progression, TGF- $\beta$ frequently switchs it's function from growth arrest to promotion of cancer cell survival, EMT, migration, invasion, vascularization, metastasis, and immunosuppression ${ }^{38}$. Hence, the immunosuppresive and pro-metastasis functions of TGF- $\beta$ may come to dominate in late-stage cancer. While the CDK inhibitors p21Cip1 and p15Ink4b mediate the inhibition of cell proliferation by TGF- $\beta$, the transcription factors such as Snail are induced by TGF- $\beta$ to promote EMT ${ }^{39}$. While EMT is generally considered a pro-tumor event, recent study also demonstrates that TGF- $\beta$ suppresses pancreatic ductal adenocarcinoma through a lethal EMT ${ }^{40}$.

Thus far, it is unknown whether SNCG is involved in TGF- $\beta$-induced cell invasion and migration. Here, we report that SNCG is a TGF- $\beta$ responsive protein. TGF- $\beta$ induces SNCG expression through Twist1, which bind to Eboxes in the promoter of SNCG thereby stimulating SNCG transcription. SNCG promotes TGF- $\beta$ - and Twist1-induced cancer cell invasion and migration. SNCG knockdown inhibits the promotion of cancer metastasis by Twist 1 .

\section{Results}

\section{Twist1 upregulates SNCG expression}

To decipher the regulatory mechanism of SNCG expression in cancer cells, we analyzed human SNCG promoter. There are multiple consensus E-boxes in human SNCG promoter (Supplementary Fig. 1). Twist1 is an $\mathrm{E}$ protein that binds to E-box thereby regulating gene expression. To determine whether Twist1 regulates SNCG expression, HepG2 cells were transfected with or without Twist1 small interfering RNA (siRNA) (siTwist1\#1 or siTwist1\#2), followed by real-time reverse transcription (RT)-PCR analysis of SNCG and Twist1 transcription. Knockdown of Twist1 by two sets of siRNA consistently led to a decrease in SNCG transcription (Fig. 1a). Moreover, Twist1 knockdown inhibited SNCG expression at protein level (Fig. 1b). Similar effects were detected in HeLa cells (Fig. 1a, b). Knockdown of Twist1 by the third siRNA (siTwist1\#3) targeting 3 '-untranslated region of Twist1 also inhibited SNCG expression (Fig. 1c). Overexpression of siTwist1\#3-resistant Twist1 upregulated SNCG expression and rescued the decrease in SNCG expression resulting from Twist1 knockdown (Fig. 1c). Taken together, these data demonstrate that Twist1 positively regulates SNCG expression.

\section{Twist1 upregulates SNCG transcription through E-boxes in SNCG promoter}

To elucidate the mechanisms underlying the upregulation of SNCG transcription by Twist1, we analyzed the effects of Twist1 on the activity of SNCG promoter. We prepared a luciferase reporter containing the 5-flanking region of $S N C G$ gene $(-1 /-2486 \mathrm{bp})$, in which there are 16 consensus E-boxes (Supplementary Fig. 1). The luciferase reporter analysis revealed that Twist1 knockdown resulted in a significant decrease in SNCG promoter activity (Fig. 2a). To further investigate how Twist1 regulates SNCG transcription, we analyzed two deletion mutants of SNCG promoter (-129/-1026del; -1260/ $-2459 \mathrm{del}$ ) (Fig. 2b). The promoter activity of -129 / -1026del mutant (SNCG pro-129/-1026del) was significantly lower than that of wild-type promoter (SNCG pro-WT), while the promoter activity of $-1260 /-2459$ del mutant (SNCG pro-1260/-2459del) was similar to that of wild-type promoter (SNCG pro-WT) (Fig. 2c). Whereas Twist1 overexpression stimulated the promoter activity of SNCG pro-WT and SNCG pro-1260/ -2459 del to similar extent, it failed to stimulate the promoter activity of SNCG pro-129/-1026del (Fig. 2d), suggesting that the $-129 /-1026$ bp region within SNCG promoter is critical for the stimulation of SNCG transcription by Twist1. 

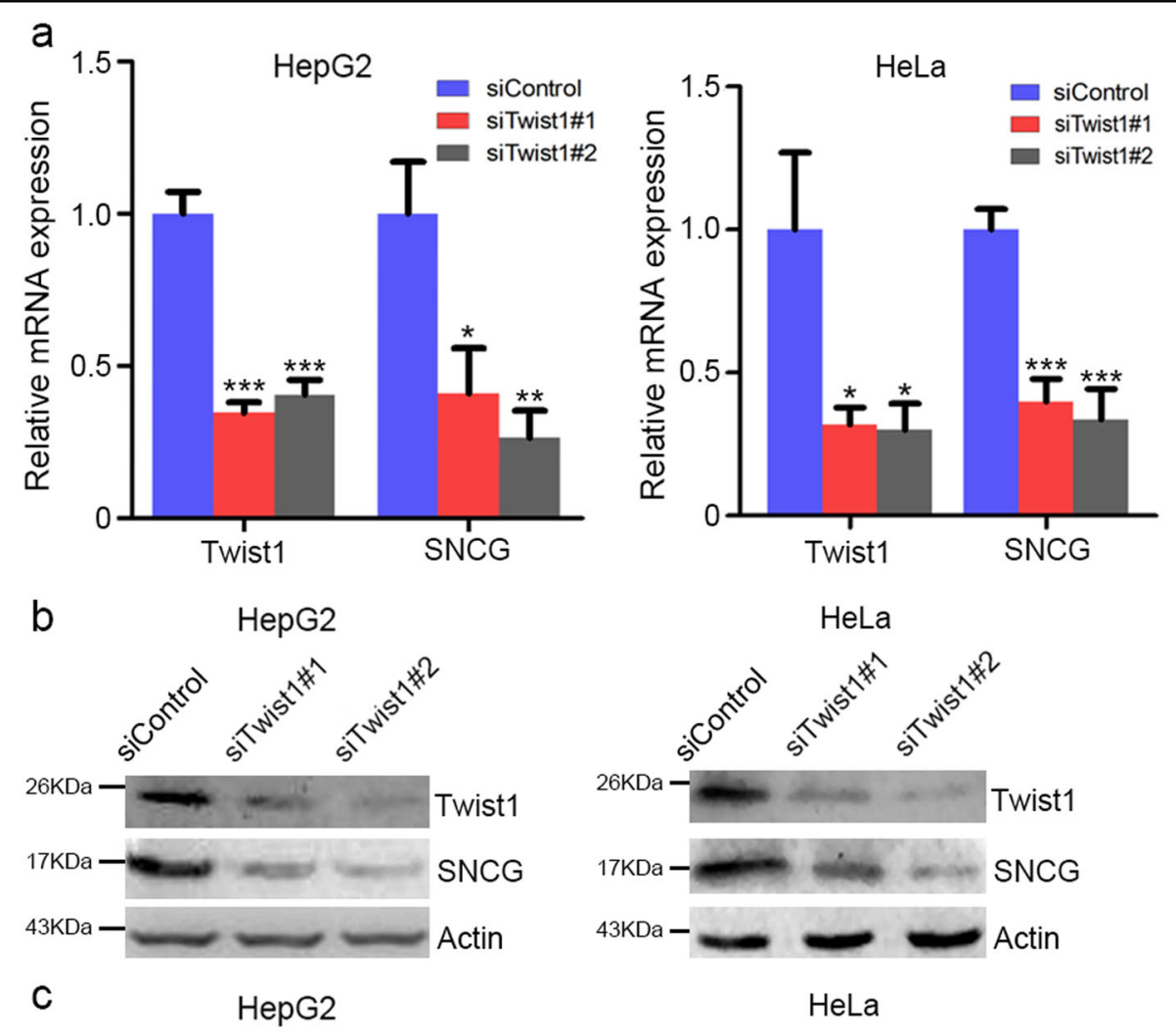

HeLa
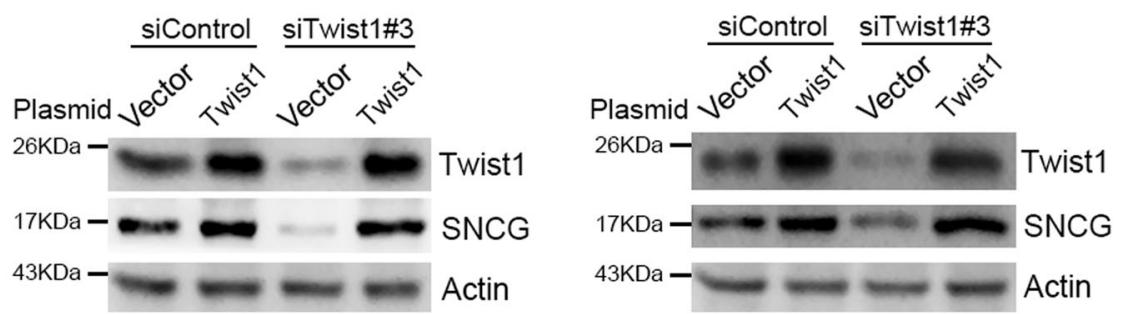

Fig. 1 Twist1 upregulates SNCG expression. a HepG2 and HeLa cells were transfected with $50 \mathrm{nM}$ of the indicated siRNA. Twenty-four hours after transfection, qRT-PCR was conducted using the primers for Twist1, SNCG, and GAPDH. The relative mRNA expression was plotted. The level of transcripts in cells transfected with control siRNA (siControl) was set as 1. The values represent mean \pm S.D. $(n=3) .{ }^{*} p<0.05 ; *^{* *} p<0.01 ;{ }^{* * *} p<0.001$, compared with siControl. $\mathbf{b}$ HepG2 and HeLa cells were transfected with $50 \mathrm{nM}$ of the indicated siRNA. Forty-eight hours after transfection, whole-cell extracts were analyzed by western blot analysis with indicated antibodies. c HepG2 and HeLa cells were transfected with $50 \mathrm{nM}$ of the indicated siRNA. Twenty-four hours after transfection, the cells were transfected with $1 \mu \mathrm{g} / \mathrm{ml}$ of the indicated plasmid. Forty-eight hours after transfection, whole-cell extracts were analyzed by western blot analysis with indicated antibodies

There are three putative E-boxes within $-129 /-1026$ bp region, namely E1, E2, and E3 (Fig. 2b). Chromatin immunoprecipitation (ChIP) assays demonstrated that endogenous Twist1 was preferentially recruited to E1and E3-containing regions, while it was also recruited to E2-containing region to a lesser extent (Fig. 2e). No binding was detected within a distal region $(-1892$ to -2031 bp) (Fig. 2e), although there are putative E-boxes within this region (Supplementary Fig. 1). To further confirm the regulation of SNCG transcription by Twist1binding via E-boxes, we analyzed the effects of Twist1 overexpression on E-box-disrupted mutants of SNCG promoter (Fig. 2f). Mutations in E1 and E3 reduced SNCG promoter activity and blunted the stimulation of SNCG promoter activity by Twist1, whereas E2 mutation had no effects on SNCG promoter activity (Fig. 2g). Compared with E3 mutation, E1 mutation more significantly affected SNCG promoter activity (Fig. 2g). Taken together, these data demonstrated that Twist1 directly binds and transactivates SNCG promoter, and confirms that SNCG is a downstream target of Twist1. The E-box mostly close to the transcription start site was critical for SNCG promoter activity and Twist1-induced SNCG transcription. 


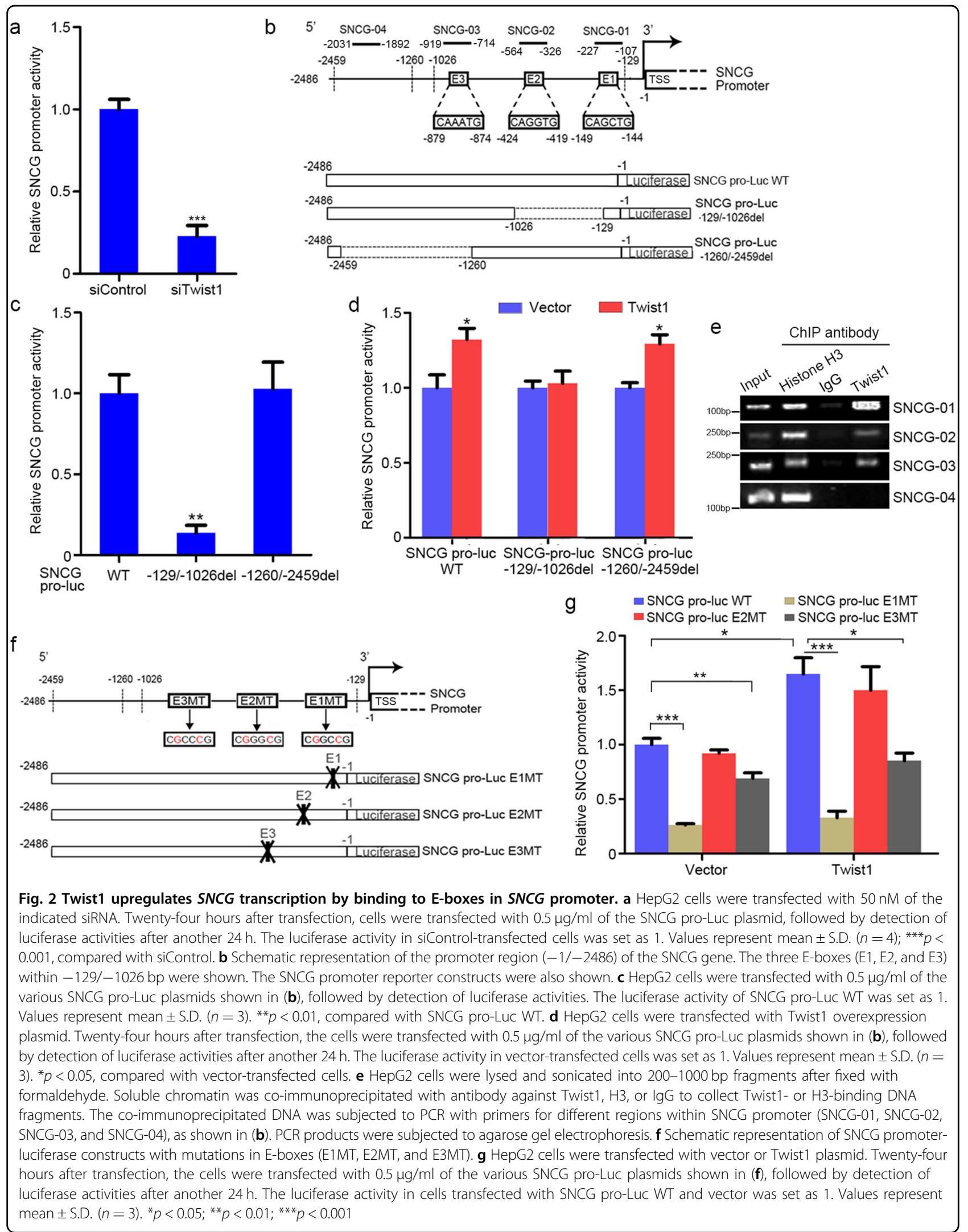



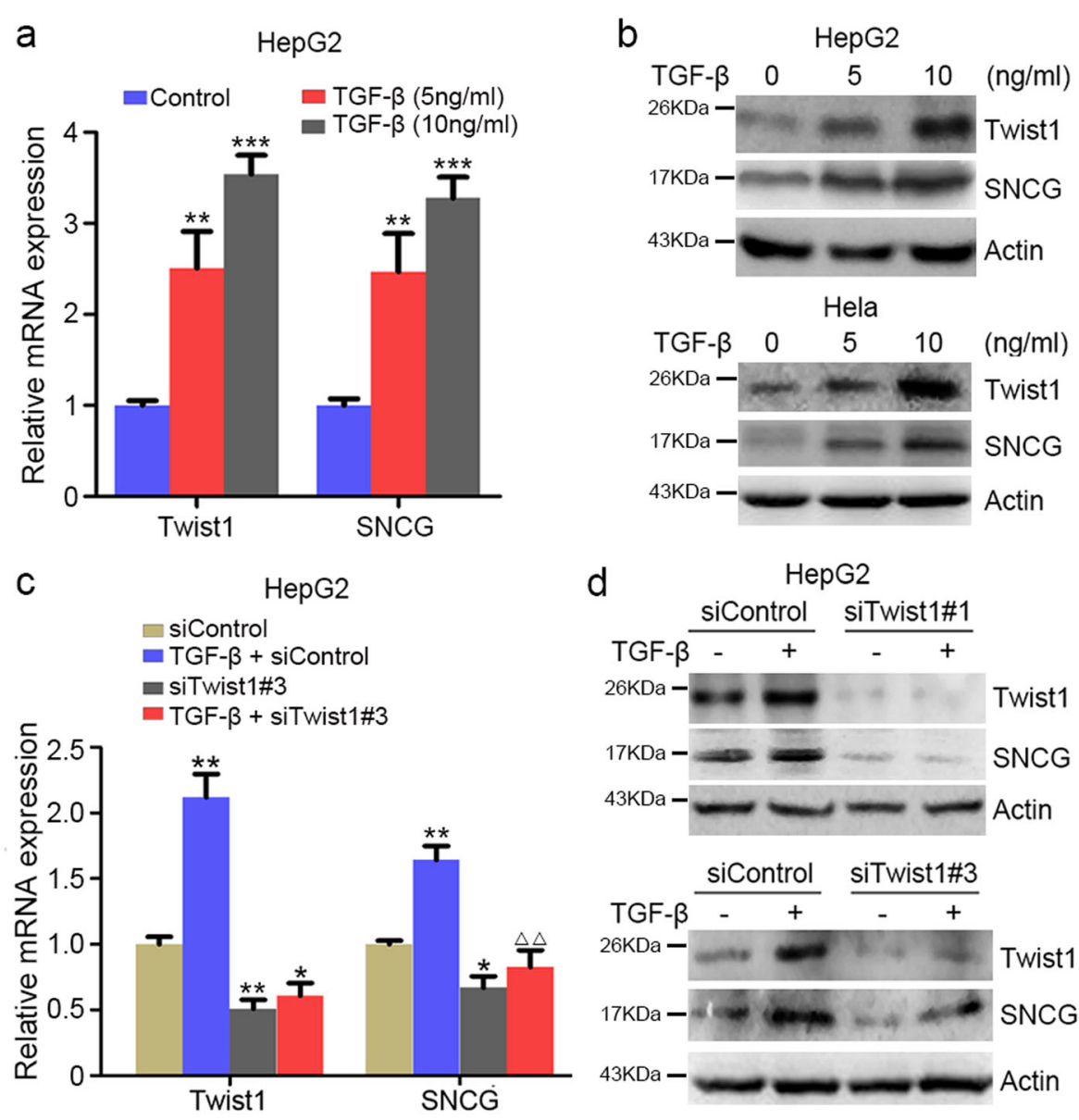

Fig. 3 TGF- $\beta$ induces SNCG expression via Twist1. a HepG2 cells were treated with or without TGF- $\beta$ for $24 \mathrm{~h}$ at indicated doses, followed by qRTPCR using the primers for Twist1, SNCG, and GAPDH. The levels of transcripts in vehicle-treated cells was set as 1. Values represent mean \pm S.D. $(n=3)$. ${ }^{* *} p<0.01 ;{ }^{* * *} p<0.001$, compared with control. $\mathbf{b}$ HepG2 and HeLa cells were treated with TGF- $\beta$ for $48 \mathrm{~h}$ at indicated doses. Whole-cell extracts were analyzed by western blotting with indicated antibodies. c HepG2 cells were transfected with control siRNA or siTwist1. Twenty-four hours later, the cells were treated with $5 \mathrm{ng} / \mathrm{ml}$ TGF- $\beta$ for another $24 \mathrm{~h}$, followed by qRT-PCR analysis of Twist1, SNCG, and GAPDH. The levels of transcripts in siControl-transfected cells were set as 1. Values represent mean \pm S.D. $(n=3) .{ }^{*} p<0.05,{ }^{* *} p<0.01$, compared with siControl; ${ }^{\Delta \Delta} p<0.01$, compared with cells treated with TGF- $\beta$. $\mathbf{d}$ HepG2 cells were transfected with control siRNA or siTwist1\#1, siTwist1\#3. Twenty-four hours later, the cells were treated with $5 \mathrm{ng} / \mathrm{ml}$ of TGF- $\beta$ for another $48 \mathrm{~h}$. Whole-cell extracts were analyzed by western blotting with indicated antibodies

\section{TGF- $\beta$ induces SNCG expression via Smad-Twist1 axis}

Since Twist1 is an oncogene downstream of TGF- $\beta$ signaling, we then detected whether TGF- $\beta$ could induce SNCG expression at both transcript and protein levels. Treatment of HepG2 cells with TGF- $\beta$ led to increased Twist1 and SNCG transcription in a dosedependent manner (Fig. 3a). Similar effects were detected in HeLa cells (Supplementary Fig. 2a). Also, TGF- $\beta$-induced Twist1 and SNCG expression at protein level (Fig. 3b). Moreover, Twist1 knockdown abrogated the induction of SNCG expression by TGF- $\beta$ in both HepG 2 and HeLa cells (Fig. 3c, d; Supplementary Figs. 2b, 3), indicating that TGF$\beta$ induces SNCG expression through Twist1.

To further define mechanisms by which TGF- $\beta$ regulates Twist1 and SNCG, we examined SNCG promoter activity using luciferase reporter. As shown in Fig. 4a, SNCG promoter activity was increased by TGF- $\beta$. Twist 1 depletion repressed the promoter activity of SNCG and abrogated the stimulation of SNCG promoter activity by TGF- $\beta$ (Fig. 4a). However, the activity of SNCG-E1MT promoter was significantly reduced and not affected by TGF- $\beta$ (Fig. 4b). Furthermore, ChIP assays demonstrated that Twist1 binding to SNCG promoter was enhanced by TGF- $\beta$ (Fig. 4c).

TGF- $\beta$ can induce Twist1 through Smad transctiption factors ${ }^{41}$. Indeed, Smad2/3 knockdown compromised the induction of Twist 1 by TGF- $\beta$ (Fig. 4d, e). Meanwhile, Smad $2 / 3$ knockdown led to a decrease in TGF- $\beta$-induced SNCG expression, indicating that TGF- $\beta$ induces SNCG through Smad-Twist1 axis (Fig. 4d, e). 

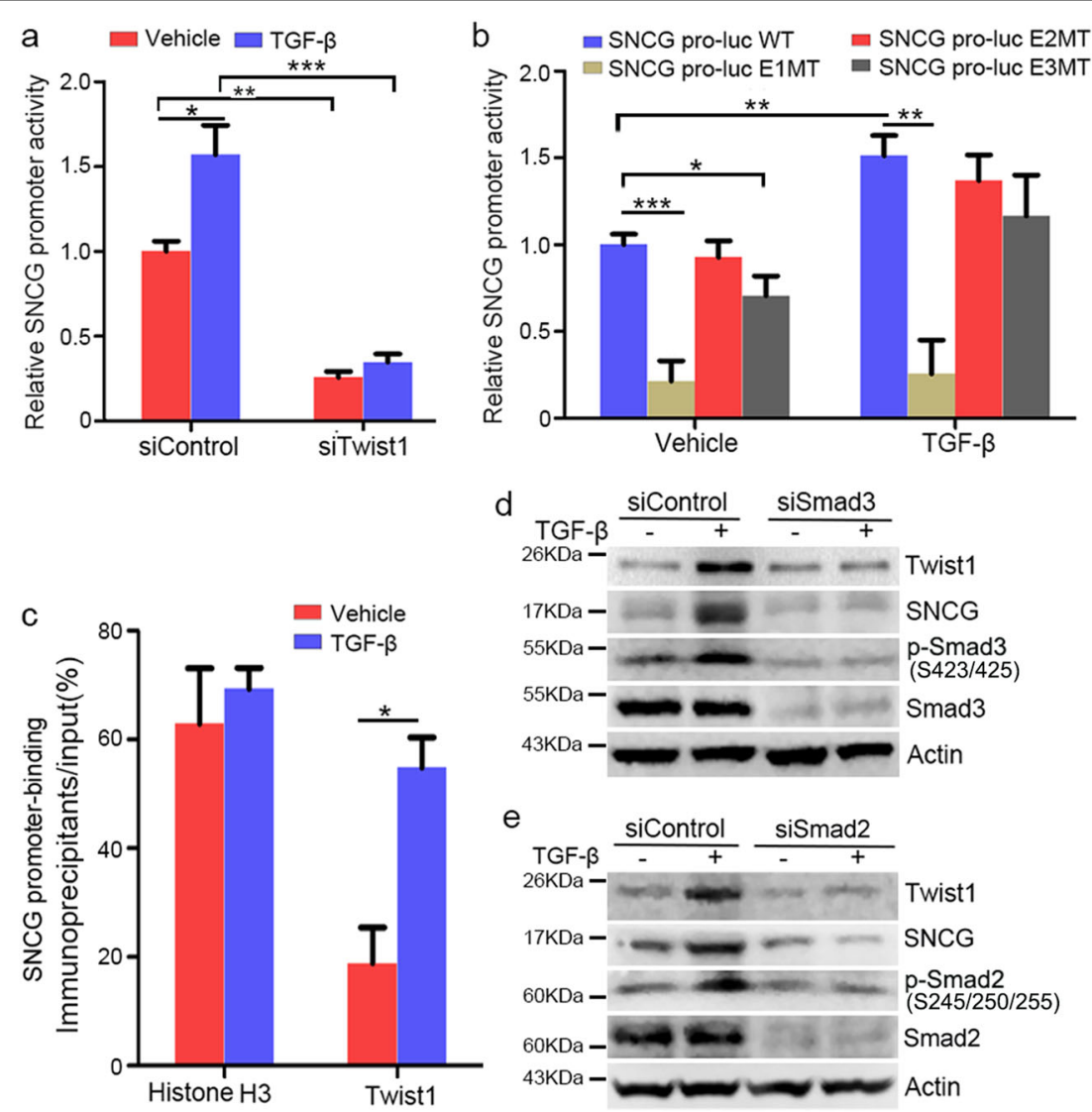

Fig. 4 TGF- $\beta$ stimulates SNCG promoter activity and induces SNCG expression through Smad-Twist1 axis. a HepG2 cells were co-transfected with $0.5 \mathrm{\mu g} / \mathrm{ml}$ of SNCG pro-Luc WT plasmid, and $50 \mathrm{nM}$ of indicated siRNA. Twenty-four hours later, the cells were treated with or without $5 \mathrm{ng} / \mathrm{ml}$ of TGF- $\beta$ for another $24 \mathrm{~h}$, followed by detection of luciferase activity. The luciferase activity in cells transfected with SNCG pro-Luc WT and siControl was set as 1. Values represent mean \pm S.D. $(n=4) .{ }^{*} p<0.05 ;{ }^{* *} p<0.01 ;{ }^{* * *} p<0.001$. b HepG2 cells were transfected with $0.5 \mu \mathrm{g} / \mathrm{ml}$ of the indicated SNCG pro-Luc plasmids. Twenty-four hours later, the cells were treated with or without $5 \mathrm{ng} / \mathrm{ml}$ of TGF- $\beta$ for another $24 \mathrm{~h}$, followed by detection of luciferase activities. The luciferase activity in cells transfected with SNCG pro-Luc WT and treated with vehicle was set as 1 . Values represent mean \pm S. D. $(n=4) .{ }^{*} p<0.05 ;{ }^{* *} p<0.01 ;{ }^{* * *} p<0.001$. c HepG2 cells were treated with or without $5 \mathrm{ng} / \mathrm{ml}$ of TGF- $\beta$ for $48 \mathrm{~h}$. Soluble chromatin was coimmunoprecipitated with antibody against Twist1 or histone $\mathrm{H} 3$ to collect Twist1- or H3-bound DNA fragments. The co-immunoprecipitated DNA was subjected to qPCR using specific primers for the SNCG promoter (SNCG-01). Values represent mean \pm S.D. $(n=3)$. ${ }^{*} p<0.05$. $\mathbf{d}$ HepG2 cells were transfected with control siRNA or siSmad3. Twenty-four hours later, the cells were treated with $5 \mathrm{ng} / \mathrm{ml}$ of TGF- $\beta$ for another $48 \mathrm{~h}$. Whole-cell extracts were analyzed by western blot analysis of indicated proteins. e HepG2 cells were transfected with control siRNA or siSmad2. Twenty-four hours later, the cells were treated with $5 \mathrm{ng} / \mathrm{ml}$ of TGF- $\beta$ for another $48 \mathrm{~h}$. Whole-cell extracts were analyzed by western blot analysis of indicated proteins

\section{SNCG knockdown inhibits TGF- $\beta$-induced cell migration and invasion}

TGF- $\beta$ promotes cancer cells invasion and migration. To determine whether SNCG is involved in TGF- $\beta$ induced cell migration and invasion, HepG2 cells were treated with or without TGF- $\beta$ and transfected with or without Twist1 and SNCG siRNA, followed by woundhealing assays. Wound area was much larger in vehicletreated group compared with TGF- $\beta$-treated cells on day 2 after wounding, indicating that TGF- $\beta$ promoted HepG2 cells migration (Fig. 5). Knockdown of Twist1 or SNCG inhibited cell migration and compromised the promotion of cell migration by TGF- $\beta$ (Fig. 5). Similar effects were detected when another set of Twist1 or
SNCG siRNA was transfected into HepG2 cells (Supplementary Fig. 4).

Moreover, TGF- $\beta$ promoted HepG2 cells invasion, as determined by transwell assay. Knockdown of Twist1 or SNCG abrogated the promotion of cell invasion by TGF- $\beta$ (Fig. 6a). Similar effects were detected in HeLa cells transfected with or without Twist1 and SNCG siRNA (Fig. 6b). These data demonstrate that, similar to Twist1, SNCG is a mediator of TGF- $\beta$-induced cell migration and invasion.

\section{SNCG knockdown inhibits Twist1-induced cell invasion}

Given that SNCG is a target of the oncogenic transcription factor Twist1, we then investigate whether SNCG acts downstream of Twist1 to promote cancer cell 

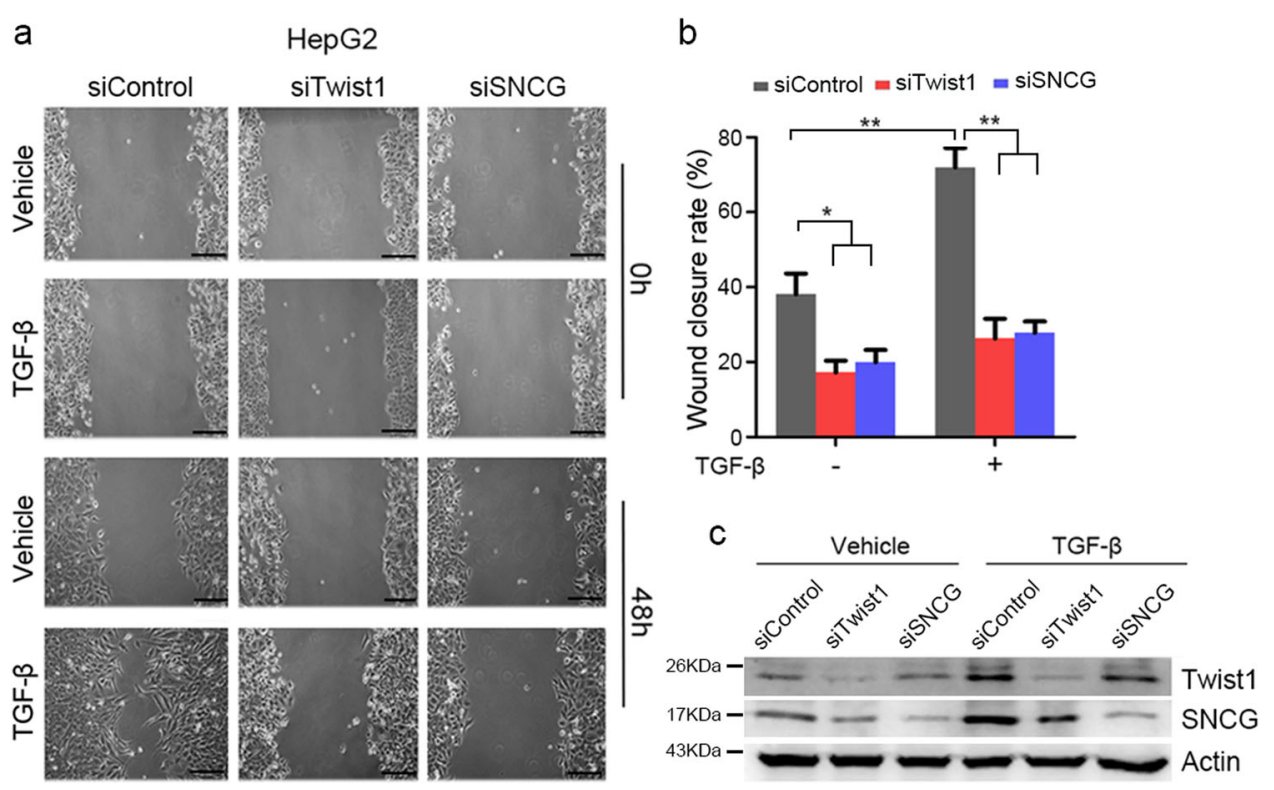

Fig. 5 SNCG knockdown inhibits TGF- $\beta$-induced cell migration. a HepG2 cells were treated with $2 \mu \mathrm{g} / \mathrm{ml}$ mitomycin and transfected with $50 \mathrm{nM}$ of indicated siRNA, and treated with or without $5 \mathrm{ng} / \mathrm{ml}$ of TGF- $\beta$, followed by wound-healing assays. Scale bar, $200 \mu \mathrm{m}$. b The wound closure rate was plotted. Values represent mean \pm S.D. $(n=6) .{ }^{*} p<0.05 ;{ }^{* *} p<0.01$. c Cell lysates were collected and subjected to western blot analysis of SNCG and Twist1 expression
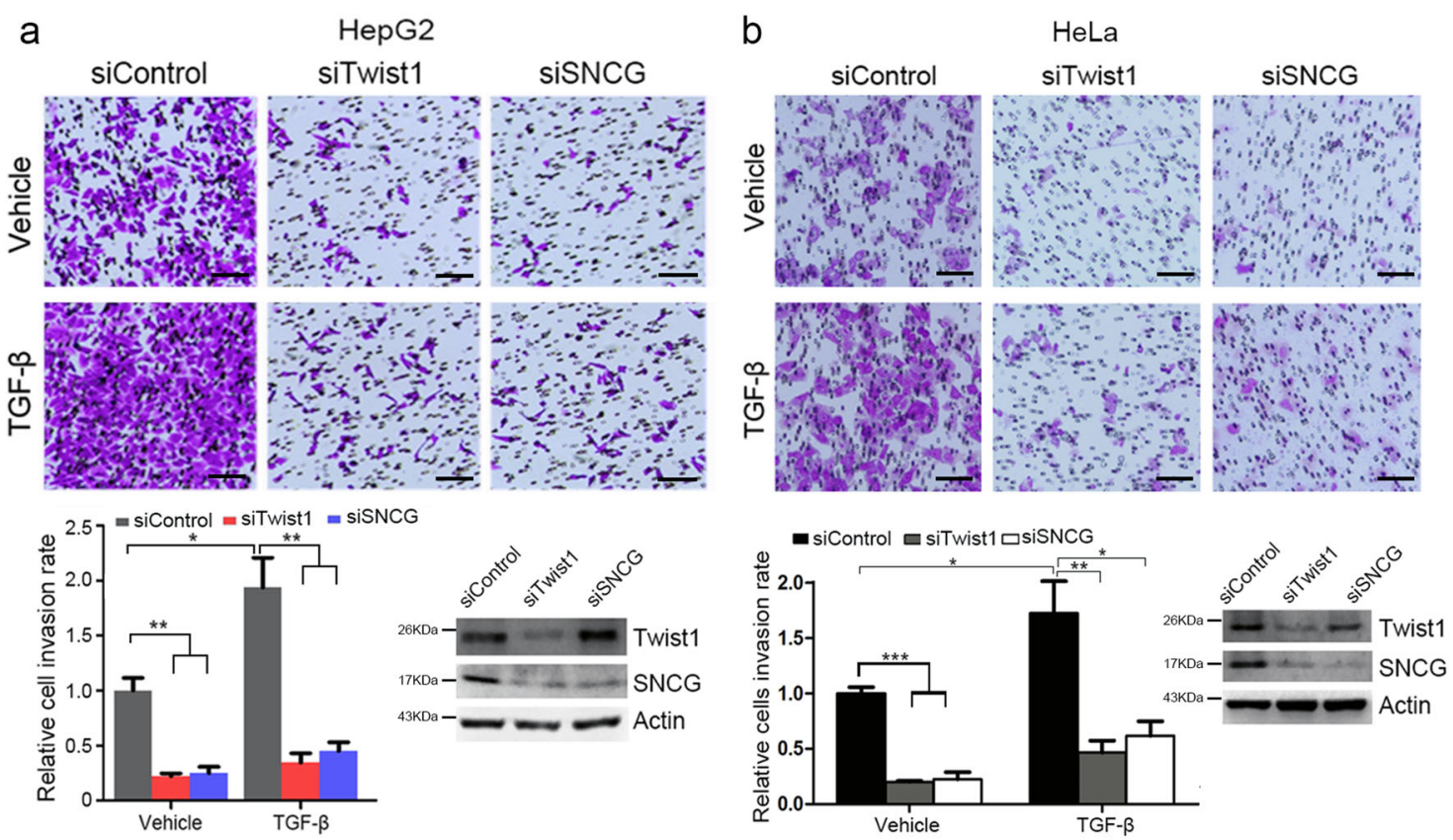

Fig. 6 Twist1 or SNCG knockdown inhibits TGF- $\beta$-induced cell invasion. a HepG2 cells were transfected with 50 nM of indicated siRNA, followed by cell invasion assays in the absence or presence of TGF- $\beta$. Scale bar, $10 \mu \mathrm{m}$. The relative cell invasion rate was plotted. Values represent mean \pm S.D. $(n=3)$. The invasion rate in siControl-transfected and TGF- $\beta$-untreated cells was set as $1 .{ }^{*} p<0.05 ;{ }^{* *} p<0.01$. In parallel, the efficiency of Twist1 or SNCG knockdown was detected by western blotting. $\mathbf{b}$ HeLa cells were transfected with $50 \mathrm{nM}$ of indicated siRNA, followed by cell invasion assays in the absence or presence of TGF- $\beta$. Scale bar, $10 \mu \mathrm{m}$. The relative cell invasion rate was plotted. Values represent mean \pm S.D. $(n=3)$. The invasion rate in siControl-transfected and TGF- $\beta$-untreated cells was set as $1 .{ }^{*} p<0.05 ;{ }^{* *} p<0.01$; ${ }^{* * *} p<0.001$. In parallel, the efficiency of Twist1 or SNCG knockdown was detected by western blotting 

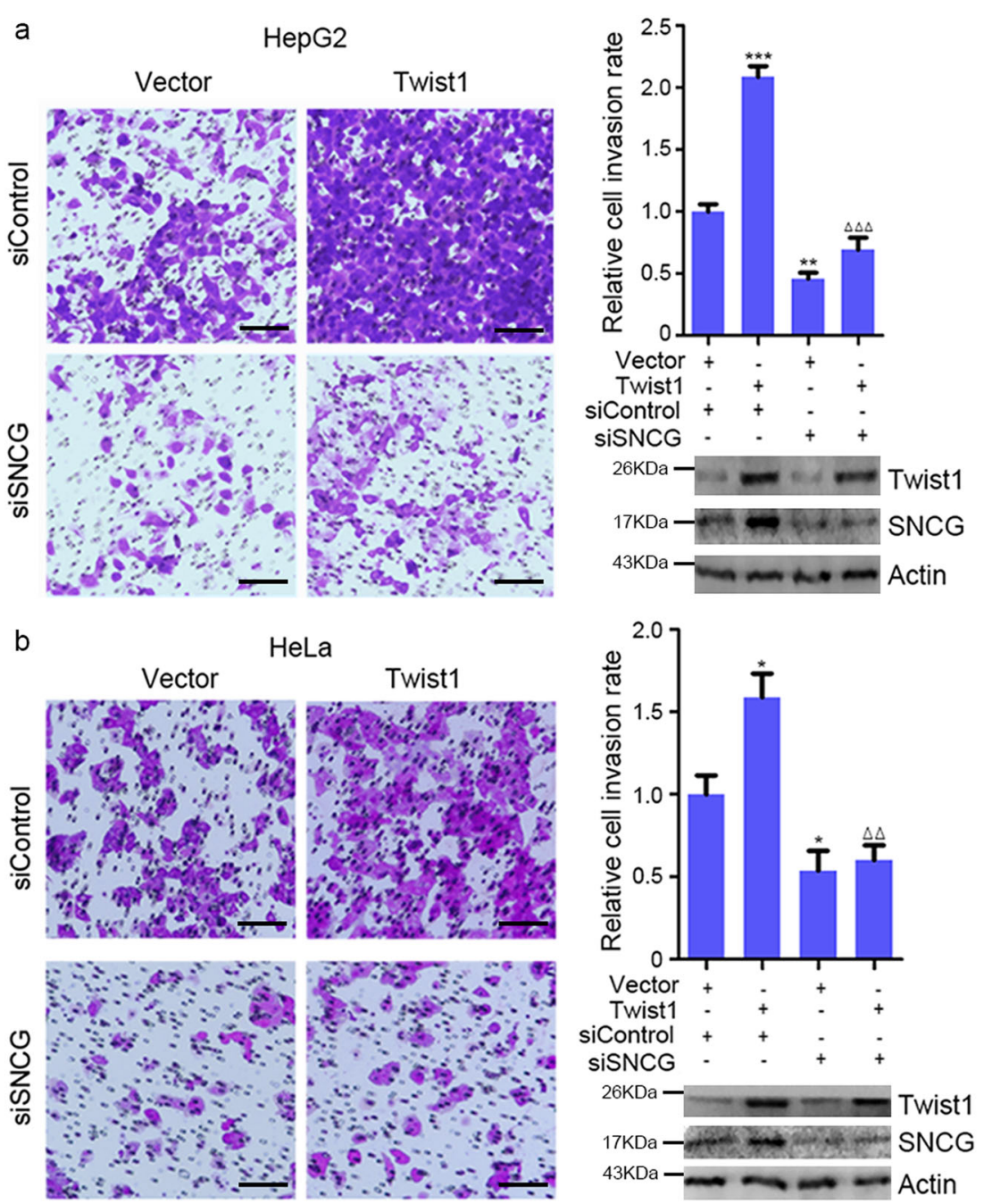

Fig. 7 SNCG knockdown inhibits Twist1-induced cell invasion. a HepG2 cells were transfected with $50 \mathrm{nM}$ of indicated siRNA and $1 \mu \mathrm{g} / \mathrm{ml}$ of Twist1 plasmid or vector, followed by cell invasion assays. Scale bar, $10 \mu \mathrm{m}$. The relative cell invasion rate was plotted. Values represent mean \pm S.D. $(n$ $=3$ ). The invasion rate in siControl- and vector-transfected cells was set as $1 .{ }^{* *} p<0.01$; ${ }^{* *} p<0.001$, compared with siControl; ${ }^{\Delta \triangle \Delta} p<0.001$, compared with siControl- and Twist1-transfected cells. In parallel, the efficiency of Twist1 overexpression or SNCG knockdown was detected by western blotting. $\mathbf{b}$ HeLa cells were transfected with $50 \mathrm{nM}$ of the indicated siRNA and $1 \mu \mathrm{g} / \mathrm{ml}$ of the Twist1-expression plasmid or vector, followed by cell invasion assays. Scale bar, $10 \mu \mathrm{m}$. The relative cell invasion rate was plotted. Values represent mean \pm S.D. $(n=3)$. The invasion rate in siControl- and vector-transfected cells was set as $1 .{ }^{*} p<0.05$, compared with siControl; ${ }^{\Delta \Delta} p<0.01$, compared with siControl- and Twist1-transfected cells. In parallel, the efficiency of Twist1 overexpression or SNCG knockdown was detected by western blotting

invasion. Indeed, overexpression of Twist1 in HepG2 cells promoted cell invasion, SNCG knockdown inhibited cell invasion and abrogated the promotion of cell invasion by Twist1 (Fig. 7a). The efficiency of Twist1 overexpression and SNCG knockdown was confirmed (Fig. 7a). Similar effects were detected in HeLa cells (Fig. 7b). These data indicate that SNCG promote cell invasion downstream of Twist1.

\section{SNCG knockdown inhibits the promotion of cancer metastasis by Twist 1}

To determine the effect of SNCG on Twist1-induced cancer metastasis, HeLa cells were stably transfected with vector or Twist1-expression plasmid, followed by lentiviral transfection of shControl or shSNCG construct. Overexpression of Twist1 and knockdown of SNCG were confirmed by western blot analysis (Fig. 8a). HeLashControl, HeLa-shSNCG, HeLa-Twist1-shControl, and HeLa-Twist1-shSNCG cells were injected into the tail vein of nude mice. Twenty-one days later, more metastatic nodules were detected in the lungs of nude mice inoculated with HeLa-Twist1-shControl cells compared with those inoculated with HeLa-shControl, HeLashSNCG, or HeLa-Twist1-shSNCG cells (Fig. 8b). Further analysis demonstrated that there were significantly more lung nodules larger than $1 \mathrm{~mm}$ in diameter in nude mice 


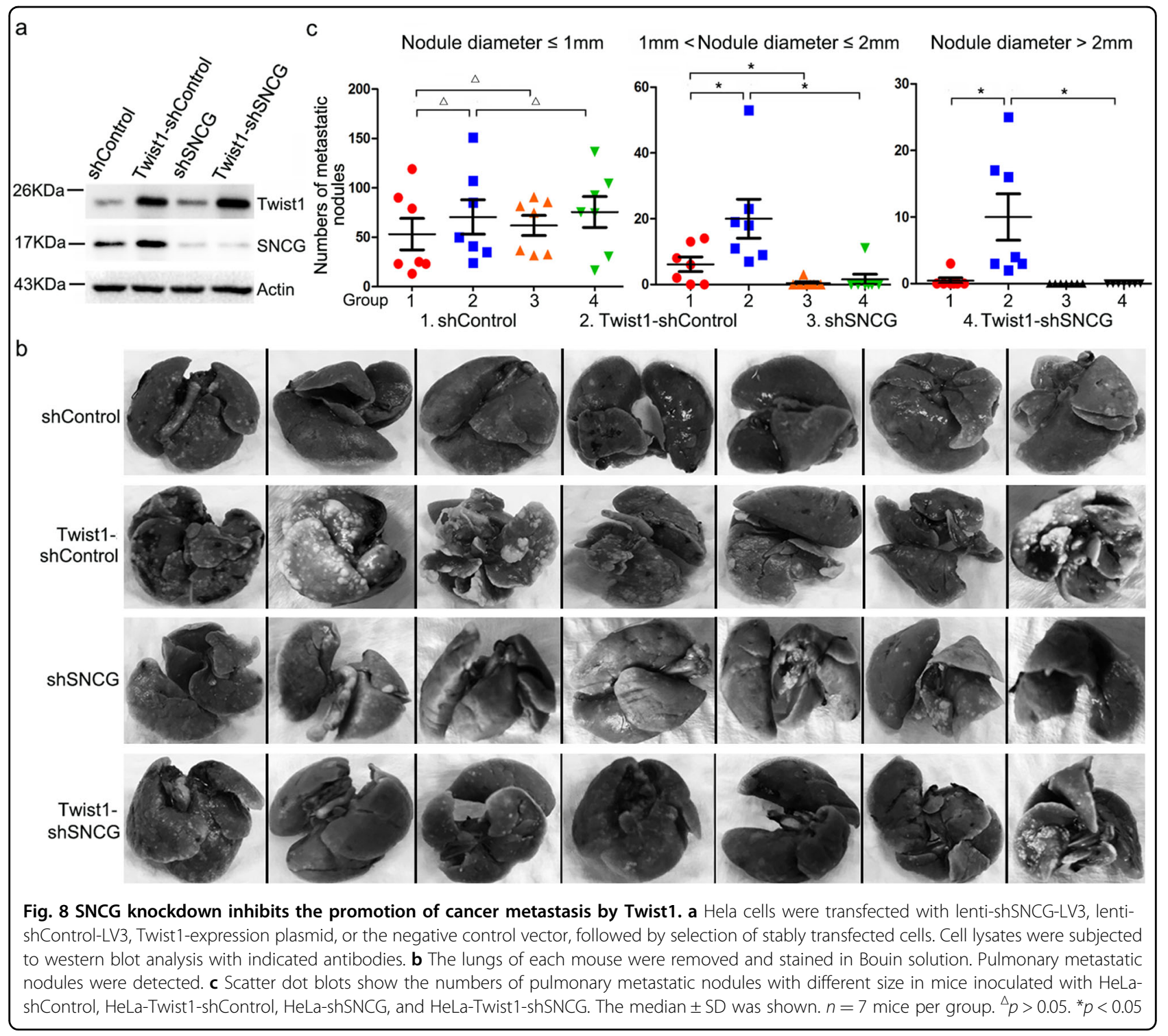

inoculated with HeLa-Twist1-shControl cells compared with other groups (Fig. 8c). Moreover, significantly less lung nodules larger than $1 \mathrm{~mm}$ in diameter were detected in nude mice inoculated with HeLa-shSNCG cells compared with those inoculated with HeLa-shControl cells (Fig. 8b, c). Taken together, these data indicate that both Twist1 and SNCG promote the metastatic potential of HeLa cells, and SNCG knockdown inhibits the promotion of HeLa metastasis by Twist1.

\section{Discussion}

TGF- $\beta$ elicits cellular phenotypic changes that establish its role both as a tumor suppressor and a tumor promoter, depending on the contextual cues both in tumor cells and tumor microenvironment ${ }^{37,42}$. TGF- $\beta$ can inhibit cell proliferation by inducing the $\mathrm{CDK}$ inhibitors p21Cip1 and
p15Ink4b, and repressing c-myc and $\mathrm{ID}^{38}$. Inactivating mutations in the TGF- $\beta$ pathway represents one of the mechanisms underlying evasion of the tumor-suppressive functions of TGF- $\beta^{43}$. However, the core TGF- $\beta$ signaling aspects are intact in many cancers such as breast cancer, melanoma, and prostate cancer, in which the tumorsuppressive arm of TGF- $\beta$ is usually amputated ${ }^{42}$. TGF- $\beta$ can also enhance the migratory and invasive properties of cancer, which represents a tumor-promoting arm of TGF$\beta$. TGF $\beta 1$ expression in invasive cancer correlates with markers of tumor progression, such as metastasis, ECM deposition, and the infiltration of immune suppressive cells. The mechanisms underlying the switch of TGF- $\beta$ from a tumor suppressor to tumor promoter may be complex. Alterations in Smad-transcription partners are important mechanisms underlying the shut-down of 
cytostatic programme of TGF- $\beta^{44}$. In addition, p53 mutation or loss of Smad4 may contribute to oncogenic TGF- $\beta$ signaling. In this study, we have demonstrated that SNCG also promotes oncogenic TGF- $\beta$ signaling. Given that SNCG is usually overexpressed in late-stage can$\operatorname{cer}^{11-13}$, it may be another contextual cue that boosts TGF- $\beta$-driven tumor progression.

TGF- $\beta$ induces the expression of SNCG through Twist1, which is a Smad target. Many extracellular stimuli affect cellular functions through induction of Twist1 expression or activation of Twist1 transcriptional activity $^{45,46}$. The bHLH transcription factor Twist1 regulates the expression of target genes by binding to E-box promoter elements ${ }^{47}$. SNCG promoter contains multiple putative E-boxes within regions -129 to $-1026 \mathrm{bp}$ and -1260 to -2459 bp relative to the translation start site. Our studies demonstrate that only three of those E-boxes are important for the activity of SNCG promoter and the expression of SNCG. Deletion of -1260 to $-2459 \mathrm{bp}$ region does not affect the basal promoter activity of SNCG, suggesting that it is not functionally involved in SNCG transcription. In contrast, deletion mutations suggest that the three E-boxes within the 879 bp minimal promoter region $(-879$ to $-1 \mathrm{bp})$ are important for the expression of SNCG, as deletion of this region or mutation of these E-boxes markedly reduced the basal- and TGF- $\beta$-induced promoter activity. Among the three Eboxes within the $879 \mathrm{bp}$ minimal promoter region, the Ebox close to the translation start site is most critical for SNCG transcription, as mutation of this E-box dramatically reduced basal- and TGF $\beta$ - or Twist1-induced reporter activity.

The aberrant expression of SNCG in cancer cells is likely controlled by multiple mechanisms. Previous studies demonstrate that demethylation of the $\mathrm{CpG}$ islands in SNCG promoter, aberrant AP1 transactivation, and IGF signaling stimulates SNCG expression ${ }^{13-15}$. The data presented herein clearly demonstrate that Twist1 is another positive regulator for SNCG transcription. Our finding that TGF- $\beta$ and Twist1 positively regulate SNCG expression identifies an important signaling pathway that leads to the activation of SNCG gene.

Both TGF- $\beta$ and Twist1 promote cancer metastasis ${ }^{24}$. The current study demonstrates that SNCG knockdown abrogates TGF- $\beta$ - and Twist1-induced cancer cell migration and invasion, indicating that SNCG is a novel mediator of the oncogenic TGF- $\beta$-Twist1 axis. While Twist1 promotes cancer metastasis, the current study demonstrates that SNCG knockdown is able to inhibit the promotion of cancer metastasis by Twist1, suggesting that SNCG may be a pro-metastatic effector downstream of Twist1. Previous studies have demonstrated that overexpression of SNCG is correlated with cancer metastasis $^{11-13,16,18}$. Mechanistically, SNCG may enhance cancer cell motility through activation of RHO family small-GTPases and ERK ${ }^{48}$. SNCG may promote cancer progression downstream of Smad-Twist1 axis in TGF- $\beta$ signaling. Elucidation of the molecular mechanism underlying the aberrant expression of SNCG in cancer may provide insights into the development of therapeutic approaches to antagonize SNCG expression and to inhibit cancer progression.

\section{Materials and methods \\ Cell culture}

Hepatoma cancer cell lines HepG2, cervical cancer cell lines HeLa were obtained from Cell Lines Bank, Chinese Academy of Science (Shanghai, China). The cells were maintained in DMEM supplemented with $10 \%$ new born calf serum (Thermo Fisher Scientific, Waltham, MA, USA). The cells were incubated at $37^{\circ} \mathrm{C}$ in a humidified atmosphere of $5 \% \mathrm{CO}_{2}$.

\section{Reagents and antibodies}

TGF- $\beta$ was purchased from PeproTech (USA). The antibodies used were as follows: anti-Twist1 was purchased from Abcam (Cambridge, UK); anti-SNCG and anti- $\beta$-actin were purchased from Santa Cruz Biotechnology (Santa Cruz, CA, USA); anti-Smad2 and antiSmad3 were purchased from ABclonal (Wuhan, China); anti-phospho-Smad2 (S245/250/255) and anti-phosphoSmad3 (S423/425) were from Cell Signaling Technology (Danvers, MA, USA). All siRNAs were customsynthesized products of Ribobio Co., Ltd. (Guangzhou, China). The siR-Ribo negative control (siControl) was used for all siRNA experiments. The target sequences for Twist1 knockdown are as follows: 5'-GGUACAUCG ACUUCCUCUA-3' for siTwist1\#1, and 5'-UUGAGGG UCUGAAUCUUGCUCAGCU-3' for siTwist $1 \# 2$. The sequence of siRNA targeting the $3^{\prime}$-untranslated region of Twist1 gene (siTwist $1 \# 3$ ) is $5^{\prime}$-CACCTCTGCATTCTG ATAGAA-3'. The two target sequences for SNCG knockdown are as follows: 5'-GCAGCTGAGAAGAC CAAGG-3' for siSNCG\#1 and 5'-GGAGAATGTTGTAC AGAGC-3' for siSNCG\#2. Target sequences for Smad3 are 5'-GGAGAAAUGGUGCGAGAAG-3'.

\section{Plasmids construction}

Plasmid for Twist1 (pBABE-puro-mTwist1\#1783) was purchased from Addgene (Cambridge, MA, USA). The complementary DNAs (cDNAs) were subcloned into pcDNA3.1(+) (Invitrogen). PGL3 luciferase reporter vectors contain four plasmids: PGL3-Basic vector, PGL3Enhancer vector, PGL3-Promoter vector, and PGL3Control vector, were purchased from Promega (Madison, USA). The SNCG promoter $(-1 /-2486 \mathrm{bp})$ reporter (SNCG pro-Luc WT) was constructed by our own laboratory. The cDNAs encoding SNCG promoter region 
were amplified by PCR from HepG2 cells by using following primer pairs: 5'-CGGGGTACCGGGCAGGCGGG AATGAGGTTTCTC-3' (forward) and 5' -CCCAA GCTT GGTGGGTGTGCAGGGTTGTGCTG-3' (reverse), and then subcloned into PGL3-Basic Vector (Promega). Various derivatives of SNCG promoter plasmids (SNCG proLuc -129/-1026del; SNCG pro-Luc -1260/-2459del) were amplified by PCR from SNCG pro-Luc WT plasmid using following primer pairs: 5'-AGCTCTGCAGATCAG AGAGGCTAGTACT-3' (forward) and 5'-ATGGAGAA ACCTCATTCCCGCCTGCCC-3' (reverse) for SNCG pro-Luc -1260/-2459del.; 5'-TTTCATCGGCGTCAAT AGGAGGCATC-3' (forward) and 5'-GCCACTTCCTCT CTTTGTTGTCCTCG-3' (reverse) for SNCG pro-Luc $-129 /-1026$ del. Mutated SNCG promoter reporter (SNCG pro-Luc E1MT; SNCG pro-Luc E2MT; SNCG pro-Luc E3MT) were constructed by GENEWIZ (Suzhou, China). Lentiviral vectors for short hairpin RNA against SNCG (shSNCG) and shControl were purchased from GenePharma (Shanghai, China).

\section{Transfection}

For transient transfection of plasmids, cells were transfected using Lipofectamine 2000 (Thermo Fisher Scientific, Waltham, MA, USA). For transfection of siRNA, proliferating cells in six-well plates were incubated with $50 \mathrm{nM}$ siRNA in $2 \mathrm{ml}$ of OPTI-MEM ${ }^{\oplus}$ I Reduced Serum Medium (Life Technologies, Carlabad, CA, USA) containing Lipofectamine RNAiMAX (Thermo Fisher Scientific). Lentiviral packaging of recombinant vectors of lenti-shSNCG-LV3 or lenti-shControl-LV3 targeting SNCG gene sequences or a nonsense sequences was produced in $293 \mathrm{~T}$ cells using a standard protocol. Fortyeight hours after transfecting HeLa cells with these lentivirus, the cells were treated with $2 \mu \mathrm{g} / \mathrm{ml}$ of puromycin. Two weeks later, the puromycin resistant clones were selected and expanded in $1 \mu \mathrm{g} / \mathrm{ml}$ puromycin-containing growth medium. Knockdown of SNCG was confirmed by western blot. For stable tranfection of Twist1 or the negative control vector, shControl- and shSNCGtransfected HeLa cells were transfected with pcDNA3.1Twsit1 or the negative control pcDNA3.1 using Lipofectamine 2000. Forty-eight hours later, the cells were treated with $800 \mu \mathrm{g} / \mathrm{ml}$ of G4l8 and $1 \mu \mathrm{g} / \mathrm{ml}$ puromycin. Two weeks later, the G418-resistant clones were selected and expanded in $400 \mu \mathrm{g} / \mathrm{ml} \quad \mathrm{G} 418$ and $1 \mu \mathrm{g} / \mathrm{ml}$ puromycin-containing growth medium.

\section{Western blot analysis}

Whole-cell extracts were obtained by lysis of cells in an appropriate volume of ice-cold radioimmunoprecipitation assay (RIPA) buffer (1\% Triton X-100, $40 \mathrm{mM}$ HEPES, $\mathrm{pH}$ 7.5, $120 \mathrm{mM} \mathrm{NaCl}, 1 \mathrm{mM}$ EDTA, $10 \mathrm{mM}$ pyrophosphate, $10 \mathrm{mM}$ glycerophosphate, $\quad 50 \mathrm{mM} \quad \mathrm{NaF}, \quad 0.5 \mathrm{mM}$ orthovanadate) containing protease inhibitors PMSF, aprotinin, and phosSTOP (Roche, Indianapolis, IN, USA). Cell lysates were incubated on ice for $35 \mathrm{~min}$ and then centrifuged for $15 \mathrm{~min}$ at $13,000 \times g$ to remove debris. Aliquots of proteins were boiled in $1 \times$ loading buffer for $10 \mathrm{~min}$, samples containing $30 \mu \mathrm{g}$ of total proteins were resolved by SDS-PAGE, and proteins transferred to PVDF membrane (Millipore Corporation, Billerica, MA, USA). Membranes were incubated with primary antibodies overnight at $4{ }^{\circ} \mathrm{C}$ and appropriate HRP-secondary antibodies for $1 \mathrm{~h}$ at room temperature. Detection was performed with chemiluminescent agents. Images were gathered by Alpha Innotech's FluorChem imaging system.

\section{Immunoprecipitation}

Cells were lysed in the RIPA buffer containing protease inhibitors. Cell lysates were incubated on ice for $30 \mathrm{~min}$ and then centrifuged for $20 \mathrm{~min}$ at 13,000 r.p.m. to remove debris. The clarified cell lysates $(1 \mathrm{mg}$ total proteins) were used for immunoprecipitation with primary antibodies or normal immunoglobulin $\mathrm{G}$ at $4{ }^{\circ} \mathrm{C}$ overnight. Then the supernatants were incubated with $30 \mu \mathrm{l}$ protein $\mathrm{G}$ agarose beads for $2 \mathrm{~h}$ at $4{ }^{\circ} \mathrm{C}$. After washing in lysis buffer five times, bound proteins were analyzed by western blotting.

\section{Quantitative reverse transcription PCR analysis}

Total RNA were extracted from cultured cells using Trizol reagent (Thermo Fisher Scientific) according to the manufacturer's protocol. First strand cDNAs were synthesized using the MMLV reverse transcriptase and oligo (dT) primers. GAPDH was amplified by real-time PCR using the SYBR ${ }^{\circ}$ Select Master Mix (Thermo Fisher Scientific). The primer sequences for human Twist1 were 5'-GTCCGCAGTCTTACGAGGAG-3' (forward) and 5' TGGAGGACCTGGTAGAGGAA-3' (reverse). The primer sequences for human SNCG were 5'-ATGCGGC TGCCCACGCTCCT-3' (forward) and 5'-GTCTTGGC TCCCACATACAT-3' (reverse). The primer sequences for GAPDH were 5'-AATCGCATCATCATAACCTG-3' (forward) and 5'-CATCCTGCCCATCATACTC-3' (reverse). Relative quantification with the comparative threshold cycle $(\mathrm{Ct})$ was done using the $\mathrm{Ct}$ method. The amount of Twist1 and SNCG, normalized to the endogenous reference gene $(G A P D H)$ is given by $2-\triangle \mathrm{Ct}$, where $\triangle \mathrm{Ct}$ is $\mathrm{Ct}$ (Twist1 or SNCG) - Ct (GAPDH).

\section{Luciferase reporter assay}

Cells were seeded in 24-well plates, then transfected with the indicated reporter plasmid, expression plasmid, siRNA, and pRL-TK as an internal control. The luciferase activities were measured using a dual-luciferase reporter assay system (Promega, BioSciences, San Luis Obispo, CA, USA) and a luminometer (Thermo Fisher, Waltham, 
USA). The Firefly luciferase activities were normalized by the corresponding Renilla luciferase activities.

\section{Chromatin immunoprecipitation assay}

ChIP assays were performed with the ChIP system according to the manufacturer's instructions (Millipore Corporation, Billerica, MA, USA). Briefly, cells were fixed with formaldehyde for $10 \mathrm{~min}$ at room temperature. After washing twice with $1 \times$ cold PBS containing proteinase inhibitor cocktail II, the cells were scraped and lysed with cell lysis buffer and nuclear lysis buffer, and then the DNA was broken into pieces $200-1000$ bp in length by sonication. Soluble chromatin was co-immunoprecipitated with antibody against Twist1, H3, or IgG at $4{ }^{\circ} \mathrm{C}$ overnight. The de-crosslinked DNA samples were subjected to PCR. The primer sequences for SNCG-01 were $5^{\prime}$-TGG AGGGATGAACTGAGATA-3' (forward) and 5'-ATCC TGCTGATGAGGTGTT- $3^{\prime}$ (reverse). The primer sequences for SNCG-02 were 5'-AGGGACTCTGGGAA TGTGG-3' (forward) and 5'-TGCTGAAGGTGCTGA GGAG-3' (reverse). The primer sequences for SNCG-03 were $5^{\prime}$-AGGATGCTGGTGGGTAGCT-3' (forward) and 5'-CAACCTGTCCCTCATTCATTTA-3' (reverse). The primer sequences for SNCG-04 were 5'-TGGAGGAA GGTGAGGCTGAA-3' (forward) and 5'-CTCCTATTGA CGCCGATGAA-3' (reverse).

\section{Cell migration and invasion assay}

Cell migration was determined by wound-healing assay. Cells were seeded in six-well plates at 50,000 cells per well. Twenty-four hours after the plating, the cells were treated with $2 \mu \mathrm{g} / \mathrm{ml}$ mitomycin $\mathrm{C}$ to inhibit cell proliferation. The indicated siRNA or plasmid was transfected into the cells. Twenty-four hours after transfection, a wound was made in the monolayer by pressing a pipette tip down on the plate. The debris was removed by washing the monolayer twice with serum-free media, and the cells were cultured in serum-free media with or without $5 \mathrm{ng} / \mathrm{ml}$ of TGF- $\beta$ for an additional 48 or $72 \mathrm{~h}$. Cell migration was recorded in six different microscopic fields. The area of scratch was recorded by taking images under a phase-contrast microscope and the gap width was measured by NIS-Elements F3.0 imaging system (Bio-Rad Laboratories, Hercules, CA, USA). The percentage of wound healing was calculated by the equation: (percentage of wound healing) $=$ average of [(gap area: $0 \mathrm{~h})$ - (gap area: 48 or $72 \mathrm{~h}$ )/(gap area: $0 \mathrm{~h}$ )].

Cell invasion was detected using transwell chambers (Millipore Corporation, Billerica, MA, USA) with Matrigel (BD Biosciences) covered. Each chambers were uniformly covered with $60 \mathrm{ml}$ Matrigel diluted with DMEM to a certain percentage and incubated at $37^{\circ} \mathrm{C}$ for $1 \mathrm{~h}$. HepG2 cells $\left(8 \times 10^{4}\right)$ or HeLa cells $\left(1 \times 10^{5}\right)$ transfected with the indicated siRNA or plasmid were applied in the upper compartment with $500 \mu \mathrm{l}$ of serum-free medium, and the lower compartment was filled in $500 \mu \mathrm{l}$ of DMEM with or without $10 \mathrm{ng} / \mathrm{ml}$ of TGF- $\beta$. After $24-48 \mathrm{~h}$ of incubation at $37^{\circ} \mathrm{C}$ (HepG2, 24-36 h; HeLa, 36-48 h), noninvaded cells on the upper surface of the filter were removed carefully with a cotton swab, and cells were fixed with $100 \%$ methanol for $2 \mathrm{~min}$. Invaded cells on the lower side of the filter were stained with $0.5 \%$ crystal violet for 20 $\mathrm{min}$, and images were captured using a fluorescence microscope. The invaded cells' area on the lower side of the filter was evaluated by Image Pro Plus 6.0. software.

\section{In vivo cancer metastasis assay}

Five-week-old female athymic nu/nu mice were purchased from Slaccas Company (Shanghai, China) and randomly divided into four groups of 7 mice each. $2 \times 10^{6}$ HeLa-shControl, HeLa-shSNCG, HeLa-Twist1-shControl, and HeLa-Twist1-shSNCG cells were resuspended in $0.2 \mathrm{ml}$ of PBS and injected into the tail vein of nude mice, respectively. Mice were killed at 21 days post injection. The lungs of each mouse were removed. To quantify lung metastasis, lungs were stained in Bouin solution for $48 \mathrm{~h}$, followed by rinsing with $70 \%(\mathrm{v} / \mathrm{v})$ ethanol. The size of metastatic nodules was measured under anatomy microscope. Animal handling and procedures were approved and performed according to the requirements of the Institutional Animal Care and Use Committee of West China Hospital.

\section{Statistical analysis}

One-way analysis of variance with post hoc tests was used in statistical analysis of messenger RNA expression, luciferase activity, cell migration, and invasion. For statistical analysis of lung metastasis, $p$ values were calculated by unpaired Student's $t$-tests. All statistical tests were two-tailed. Differences were considered statistically significant if $p<0.05$.

\section{Acknowledgements \\ This work was supported in part by National Natural Science Foundation of China (81672814). We would also like to thank Qiulin Tang for her assistance in techinical aspects. \\ Author details \\ ${ }^{1}$ State Key Laboratory of Biotherapy, Section of Oncogene, Cancer Center, West China Hospital, Sichuan University and Collaboratory Inovation Center for Biotherapy, Chengdu, China. 'Laboratory of Stem Cell Biology, West China Hospital, Sichuan University, Chengdu, China. ${ }^{3}$ School of Basic Medicine, Chengdu University of Traditional Chinese Medicine, Chengdu, China. ${ }^{4}$ Cancer Center, West China Hospital, Sichuan University, Chengdu, China}

Conflict of interest

The authors declare that they have no conflict of interest.

\section{Publisher's note}

Springer Nature remains neutral with regard to jurisdictional claims in published maps and institutional affiliations. 
Supplementary Information accompanies this paper at (https://doi.org/ 10.1038/s41419-018-0657-z).

Received: 28 November 2017 Revised: 19 April 2018 Accepted: 2 May 2018 Published online: 24 May 2018

\section{References}

1. Burre, J. et al. Alpha-synuclein promotes SNARE-complex assembly in vivo and in vitro. Science 329, 1663-1667 (2010).

2. Diao, J. et al. Native a-synuclein induces clustering of synaptic-vesicle mimics via binding to phospholipids and synaptobrevin-2/VAMP2. eLife $\mathbf{2}$, e00592 (2013).

3. Bartels, T., Choi, J. G. \& Selkoe, D. J. a-Synuclein occurs physiologically as a helically folded tetramer that resists aggregation. Nature 477, 107-110 (2011).

4. Theillet, F. X. et al. Structural disorder of monomeric a-synuclein persists in mammalian cells. Nature 530, 45-50 (2016)

5. Ma, Q. L., Chan, P., Yoshii, M. \& Ueda, K. Alpha-synuclein aggregation and neurodegenerative diseases. J. Alzheimer's Dis. 5, 139-148 (2003).

6. Prusiner, S. B. et al. Evidence for a-synuclein prions causing multiple system atrophy in humans with Parkinsonism. Proc. Natl Acad. Sci. USA 112 E5308-E5317 (2015)

7. Uversky, V. N. et al. Biophysical properties of the synucleins and their propensities to fibrillate: inhibition of alpha-synuclein assembly by beta- and gamma-synucleins. J. Biol. Chem. 277, 11970-11978 (2002).

8. Buchman, V. L. et al. Persyn, a member of the synuclein family, has a distinct pattern of expression in the developing nervous system. J. Neurosci. 18, 9335-9341 (1998)

9. Surguchov, A., Palazzo, R. E. \& Surgucheva, I. Gamma synuclein: subcellular localization in neuronal and non-neuronal cells and effect on signal transduction. Cell Motil. Cytoskelet. 49, 218-228 (2001).

10. Bruening, W. et al. Synucleins are expressed in the majority of breast and ovarian carcinomas and in preneoplastic lesions of the ovary. Cancer $\mathbf{8 8}$ 2154-2163 (2000).

11. Guo, J. et al. Neuronal protein synuclein gamma predicts poor clinical outcome in breast cancer. Int. J. Cancer 121, 1296-1305 (2007).

12. $\mathrm{Hu}, \mathrm{H}$. et al. Tumor cell-microenvironment interaction models coupled with clinical validation reveal CCL2 and SNCG as two predictors of colorectal cancer hepatic metastasis. Clin. Cancer Res. 15, 5485-5493 (2009).

13. Liu, $\mathrm{H}$. et al. Loss of epigenetic control of synuclein-gamma gene as a molecular indicator of metastasis in a wide range of human cancers. Cancer Res. 65, 7635-7643 (2005).

14. Li, M. et al. The reciprocal regulation of gamma-synuclein and IGF-I receptor expression creates a circuit that modulates IGF-I signaling. J. Biol. Chem. $\mathbf{2 8 5}$ 30480-30488 (2010)

15. Lu, A., Zhang, F., Gupta, A. \& Liu, J. Blockade of AP1 transactivation abrogates the abnormal expression of breast cancer-specific gene 1 in breast cancer cells. J. Biol. Chem. 277, 31364-31372 (2002)

16. Hibi, T. et al. Synuclein-gamma is closely involved in perineural invasion and distant metastasis in mouse models and is a novel prognostic factor in pancreatic cancer. Clin. Cancer Res. 15, 2864-2871 (2009).

17. Hua, $\mathrm{H}$. et al. Up-regulation of gamma-synuclein contributes to cancer cell survival under endoplasmic reticulum stress. J. Pathol. 217, 507-515 (2009).

18. Jia, T., Liu, Y. E., Liu, J. \& Shi, Y. E. Stimulation of breast cancer invasion and metastasis by synuclein gamma. Cancer Res. 59, 742-747 (1999).

19. Pan, Z. Z., Bruening, W., Giasson, B. I., Lee, V. M. \& Godwin, A. K. Gammasynuclein promotes cancer cell survival and inhibits stress- and chemotherapy drug-induced apoptosis by modulating MAPK pathways. J. Biol. Chem. 277, 35050-35060 (2002)

20. Jiang, Y., Liu, Y. E., Goldberg, I. D. \& Shi, Y. E. Gamma synuclein, a novel heatshock protein-associated chaperone, stimulates ligand-dependent estrogen receptor alpha signaling and mammary tumorigenesis. Cancer Res. 64 4539-4546 (2004)

21. Liang, W. et al. Synuclein gamma protects Akt and mTOR and renders tumor resistance to Hsp90 disruption. Oncogene 34, 2398-2405 (2015).

22. Gupta, A., Inaba, S., Wong, O. K., Fang, G. \& Liu, J. Breast cancer-specific gene 1 interacts with the mitotic checkpoint kinase BubR1. Oncogene 22, 7593-7599 (2003).
23. Elias, M. C. et al. TWIST is expressed in human gliomas and promotes invasion. Neoplasia 7, 824-837 (2005).

24. Yang, J. et al. Twist, a master regulator of morphogenesis, plays an essential role in tumor metastasis. Cell 117, 927-939 (2004).

25. Yang, M. H. et al. Comprehensive analysis of the independent effect of twist and snail in promoting metastasis of hepatocellular carcinoma. Hepatology 50, 1464-1474 (2009)

26. Howe, L. R., Watanabe, O., Leonard, J. \& Brown, A. M. Twist is up-regulated in response to Wnt1 and inhibits mouse mammary cell differentiation. Cancer Res. 63, 1906-1913 (2003).

27. Weiss, M. B. et al. TWIST1 is an ERK1/2 effector that promotes invasion and regulates MMP-1 expression in human melanoma cells. Cancer Res. 72 6382-6392 (2012).

28. Bouard, $C$. et al. Deciphering the molecular mechanisms underlying the binding of the TWIST1/E12 complex to regulatory E-box sequences. Nucleic Acids Res. 44, 5470-5489 (2016).

29. Qin, Q., Xu, Y., He, T., Qin, C. \& Xu, J. Normal and disease-related biological functions of Twist1 and underlying molecular mechanisms. Cell Res. 22, 90-106 (2012).

30. Mishra, V. K. et al. Histone deacetylase class-I inhibition promotes epithelia gene expression in pancreatic cancer cells in a BRD4- and MYC-dependent manner. Nucleic Acids Res. 45, 6334-6349 (2017)

31. Yang, M. H. et al. Direct regulation of TWIST by HIF-1alpha promotes metastasis. Nat. Cell Biol. 10, 295-305 (2008).

32. Eckert, M. A. et al. Twist1-induced invadopodia formation promotes tumor metastasis. Cancer Cell 19, 372-386 (2011).

33. Mironchik, Y. et al. Twist overexpression induces in vivo angiogenesis and correlates with chromosomal instability in breast cancer. Cancer Res. 65, 10801-10809 (2005)

34. Beck, B. et al. Different levels of Twist 1 regulate skin tumor initiation, stemness, and progression. Cell Stem Cell 16, 67-79 (2015).

35. Mani, S. A. et al. The epithelial-mesenchymal transition generates cells with properties of stem cells. Cell 133, 704-715 (2008).

36. Schmidt, J. M. et al. Stem-cell-like properties and epithelial plasticity arise as stable traits after transient Twist1 activation. Cell Rep. 10, 131-139 (2015).

37. Wrighton, K. H., Lin, X. \& Feng, X. H. Phospho-control of TGF-beta superfamily signaling. Cell Res. 19, 8-20 (2009).

38. Zhang, Y., Alexander, P. B., \& Wang, X. F. TGF- $\beta$ family signaling in the control of cell proliferation and survival. Cold Spring Harb. Perspect. Biol. 9, a022145 (2017).

39. Watabe, T. \& Miyazono, K. Roles of TGF-beta family signaling in stem cell renewal and differentiation. Cell Res. 19, 103-115 (2009).

40. David, C. J. et al. TGF- $\beta$ tumor suppression through a lethal EMT. Cell 164 1015-1030 (2016)

41. Katsuno, Y., Lamouille, S. \& Derynck, R. TGF-beta signaling and epithelialmesenchymal transition in cancer progression. Curr. Opin. Oncol. 25, 76-84 (2013).

42. Bierie, B. \& Moses, H. L. TGFbeta: the molecular Jekyll and Hyde of cancer. Nat. Rev. Cancer 6, 506-520 (2006).

43. Guasch, G. et al. Loss of TGFbeta signaling destabilizes homeostasis and promotes squamous cell carcinomas in stratified epithelia. Cancer Cell $\mathbf{1 2}$ 313-327 (2007)

44. $\mathrm{Xu}$, J. et al. 14-3-3zeta turns TGF-beta's function from tumor suppressor to metastasis promoter in breast cancer by contextual changes of Smad partners from p53 to Gli2. Cancer Cell 27, 177-192 (2015).

45. Dupont, J., Fernandez, A. M., Glackin, C. A., Helman, L. \& LeRoith, D. Insulin-like growth factor 1 (IGF-1)-induced twist expression is involved in the anti-apoptotic effects of the IGF-1 receptor. J. Biol. Chem. 276, 26699-26707 (2001).

46. Takebe, N., Warren, R. Q. \& IVy, S. P. Breast cancer growth and metastasis: interplay between cancer stem cells, embryonic signaling pathways and epithelial-to-mesenchymal transition. Breast Cancer Res. 13, 211 (2011)

47. Kophengnavong, T., Michnowicz, J. E. \& Blackwell, T. K. Establishment of distinct MyoD, E2A, and twist DNA binding specificities by different basic regionDNA conformations. Mol. Cell. Biol. 20, 261-272 (2000).

48. Pan, Z. Z., Bruening, W. \& Godwin, A. K. Involvement of RHO GTPases and ERK in synuclein-gamma enhanced cancer cell motility. Int. J. Oncol. 29, 1201-1205 (2006). 